\title{
Pesquisa e desenvolvimento na Área de saneamento no BRASIL: NECESSIDADES E TENDÊNCIAS
}

\author{
RESEARCH AND DEVELOPMENT ON ENVIRONMENTAL SANITATION IN \\ BRAZIL: NEEDS AND TRENDS
}

\author{
LÉO HELLER \\ Departamento de Engenharia Sanitária e Ambiental, Universidade Federal de Minas Gerais
}

NILO DE OLIVEIRA NASCIMENTO

Departamento de Engenharia Hidráulica e de Recursos Hídricos, Universidade Federal de Minas Gerais

Recebido: 19/04/04 Aceito: 17/09/04

\begin{abstract}
RESUMO
O artigo aborda um conjunto de dimensões envolvidas na pesquisa e desenvolvimento em saneamento, contextualizadas na realidade nacional. São discutidos os antecedentes históricos do tema, o sentido e os fins da pesquisa na área, os objetos e os métodos da investigação. Os temas da formação de recursos humanos, da divulgação, da transferência de tecnologia, do fomento e da avaliação da pesquisa são introduzidos, destacando a necessidade de seu aprofundamento. Apresenta-se uma proposta de protocolo para classificação e seleção de $P \& D$ na área e este é aplicado em caráter de exercício. $\mathrm{O}$ trabalho conclui pela constatação de diversas carências no tema, resultando nas necessidades de: inventário das iniciativas e programas existentes que fomentam a pesquisa na área; avaliação da base social sobre a qual esta se sustenta; debate sobre os objetos da investigação e sua base conceitual de suporte; debate metodológico; prospecção sobre temas de investigação, a partir de protocolo e metodologia apropriados. Finaliza-se com a proposta de elaboração de um plano diretor de pesquisas em saneamento, que forneça as bases e respalde uma futura política de pesquisas na área.
\end{abstract}

PALAVRAS-CHAVE: Saneamento, pesquisa, desenvolvimento, tecnologia, $\mathrm{P} \& \mathrm{D}$.

\begin{abstract}
The paper deals with a set of dimensions about research and development on environmental sanitation, based on the national reality. The historic background, the research sense and aim, and the investigation object and method are discussed. The themes of human resources, scientific communication, technology transfer, funding and evaluation are introduced, emphasizing the need of deeper approach. A protocol regarding classification and selection of $R \& D$ in the area is proposed and it is applied as an exercise. The paper concludes that the theme lacks several important issues, resulting on the need of: surveying the existing initiative and programs that fund researches; evaluating the social basis that support researches; discussing research objects and conceptual basis; discussing methodological frameworks; prospecting research themes, through appropriated protocol and methodology. Finally, the development of a directive plane for environmental sanitation researches, providing the basis and supporting future policies on the area, is proposed.
\end{abstract}

KEY-WORDS: Environmental sanitation, research, development, technology, R\&D.

\section{INTRODUÇÃO}

Discussões ampliadas e qualificadas sobre as desejáveis prioridades nacionais no campo da ciência e tecnologia, que efetivamente subsidiem políticas setoriais, são lamentavelmente escassas no país, ainda que esforços recentes mais gerais tenham sido desenvolvidos (Silva e Melo, 2001, MCT, 2002, 2003). Se essa assertiva é verdadeira para a ciência e tecnologia em seu âmbito global, mais do que a outros campos do conhecimento é certamente aplicável ao setor de sanea- mento em particular. É claro para os que se ocupam em avalia-lo, que o campo do saneamento vem se encontrando imerso em um ambiente de rarefeitos debates sobre o papel social que tem a cumprir e sobre a sua mais adequada moldura regulatória, legal e institucional, ainda que alguns meritórios esforços recentes possam ser percebidos. Evidentemente, tal ambiente colabora com a dificuldade em se localizarem os rumos da pesquisa e do desenvolvimento tecnológico que pudessem se alinhar a uma perspectiva de contribuição com a sociedade.
Mesmo se compreendendo que a pesquisa, básica ou aplicada, deve se constituir em um espaço de liberdade e criatividade, a partir de onde novas perspectivas possam emergir, o presente artigo parte do pressuposto de que a existência de elementos norteadores é essencial para uma consistente e convergente política na área. Não se trata aqui de contrapor pesquisa induzida com iniciativas espontâneas, uma vez que se deve buscar o adequado balanceamento entre ambas as estratégias. Mas, o princípio orientador destas reflexões assenta-se na convicção

\footnotetext{
${ }^{1}$ O presente texto corresponde a uma síntese de documento elaborado por solicitação do CGEE - Centro de Gestão e Estudos Estratégicos, concluído em dezembro/2003, visando subsidiar prospecção de temas de pesquisa em recursos hídricos coordenada por aquela entidade, por encomenda do CTHIDRO - Fundo Setorial de Recursos Hídricos
} 
de que a pesquisa e o desenvolvimento na área de saneamento, particularmente em um país com a nossa realidade, estarão tanto mais contribuindo para o desenvolvimento nacional, quanto mais atentos estiverem com o estágio tecnológico do setor e suas necessidades, face às demandas presentes e futuras do atendimento à população. Obviamente, tal perspectiva reconhece a inteira pertinência de a pesquisa nacional, em compasso com o referencial em nossa realidade, se manter absolutamente sintonizada com as tendências internacionais, mesmo com aquelas reflexões científicas que prognosticam futuras mudanças dos paradigmas que vêm orientando as opçōes tecnológicas dominantes.

Em vista deste marco referencial, mas não desconhecendo a complexidade e os múltiplos tentáculos característicos da relevante área do saneamento, estruturou-se o artigo visando subsidiar discussão a respeito do espaço institucional da pesquisa e desenvolvimento em saneamento e buscando também agregar reflexôes como uma base referencial para a indispensável construção de uma política de mais largo prazo.

A estrutura adotada consta da breve descrição histórica dos antecedentes da pesquisa em saneamento no país; uma discussão a respeito de seus objetivos (por quês e para quês), dos objetos de pesquisa (o que pesquisar), dos métodos (como?); além de se pontuarem tópicos adicionais, a exemplo da disseminação de conhecimentos e da transferência dos resultados da pesquisa. Por fim, visando subsidiar uma possível prospecção de pesquisa na área, propóe-se um protocolo específico, que foi aplicado junto a grupos de pesquisadores da Universidade Federal de Minas Gerais das áreas de abastecimento de água, esgotamento sanitário e gerenciamento de resíduos sólidos urbanos, buscando testá-lo e realizar uma primeira prospecção sobre temas prioritários de pesquisa na área. Assume-se que um protocolo como o aplicado pode se constituir em instrumento para classificação, priorização e posterior avaliação de uma política de $P \& D$ na área de saneamento.

\section{ANTECEDENTES}

A gênese da pesquisa em saneamento no Brasil guarda raízes comuns com outras iniciativas de investigação de natureza aplicada. Foi certamente no âmbito das instituições responsáveis pela provisão dos serviços que se iniciaram, ainda que não sistematicamente, investigações, testes, desenvolvimentos e avaliaçôes na área, motivados sobretudo pela transferência de técnicas e processos desenvolvidos nos países ricos e sua necessária adaptação à nossa realidade. Nesse particular, destaca-se a atuação da FSESP - Fundação Serviços Especiais de Saúde Pública e do DNERU - Departamento Nacional de Endemias Rurais - até a década de 1960 , inclusive com iniciativas pioneiras, sobretudo no campo do desenvolvimento de tecnologias apropriadas ao abastecimento de água e ao esgotamento sanitário.

Com o advento do PLANASA, na década de 1970, a par da implementação de um novo arranjo financeiro, político e institucional, localizam-se alguns esforços de incentivo à pesquisa e ao desenvolvimento na área, por um lado em decorrência de necessidades impostas pelo próprio aquecimento econômico do setor e por outro por iniciativas específicas de fomento da pesquisa. Tais esforços, certamente muito isolados e sem qualquer perspectiva de maior articulação nacional, distribuíram-se por algumas companhias estaduais de saneamento, pelos órgãos federais como a FSESP e por algumas universidades, e, em alguns casos, contaram com o apoio financeiro do então BNH - Banco Nacional de Habitação, organismo financiador das obras de saneamento. Naturalmente, a própria lógica conceitual do PLANASA restringiu o investimento em pesquisa aos campos do abastecimento de água e do esgotamento sanitário.

Porém, apenas a partir da década de 1980, identifica-se uma atuação mais sistemática e consistente de organização da pesquisa nas universidades, com o apoio à formação de doutores, à estruturação de laboratórios de pesquisa, ao fomento a projetos de investigação e à criação/consolidação da pós-graduação na área. Tal fato é essencial para a análise da evolução da pesquisa na área de saneamento, considerando ser a universidade - especialmente a pública - a instituição que concentra a quase totalidade da pesquisa no país ${ }^{2}$, embora não se deva desconhecer a existência de pesquisa e desenvolvimen- to, mesmo que em caráter disperso, em entidades prestadoras de serviço.

Nessa década, porém, talvez mais se tenha trabalhado para construir um ambiente de pesquisa que propriamente em sua realização. Ilustrativo depoimento do quadro ainda incipiente e desfocado que prevalecia até o final da década de 1980 é o artigo publicado por Ennes (1991), conhecido militante da área de saneamento, que advertia para "distorçōes ocorridas na Universidade Brasileira, ao se transpor, para o País, o modelo de pesquisa e pós-graduação das nações desenvolvidas", defendendo a luta "pela pesquisa de ponta, sem nos esquecermos de que em certas áreas, como o saneamento e a saúde pública, estamos atrasados, às vezes, mais de 40 anos; [....] em tais casos, a tecnologia apropriada pressupóe uma boa dose de criatividade e outra, maior ainda, de humildade" (grifos deste autor).

Tal evolução propiciou que as décadas de 1990 e a presente se revelassem relativamente férteis no incentivo à pesquisa no país, de forma ampla e no setor especificamente. No primeiro caso, além dos programas tradicionais de fomento à pesquisa espontânea, praticados pelas agências federais e algumas estaduais, foram lançados programas visando à consolidação de grupos de excelência, a exemplo do PRONEX e os Institutos do Milênio. No caso específico do setor ambiental e de saneamento, implementaram-se programas como o PADCT/CIAMB, a indução ao Doutorado no Exterior nas áreas de engenharia sanitária e engenharia ambiental pelo $\mathrm{CNPq}$ e, sobretudo, o $\mathrm{PROSAB}^{3}$ - mais consistente e contínuo programa de apoio induzido à pesquisa $\mathrm{e}$ desenvolvimento na área -, além de programas de pesquisa do CENEPI/FUNASA e do DENSP/FUNASA e, no âmbito dos fundos setoriais sobretudo o CTHIDRO, além de outros que vêm tangenciando o tema. É fundamental destacar que essa profusão de iniciativas, ainda que importantes e bem recebidas pela comunidade de pesquisadores, não significa necessariamente uma política de incentivo à pesquisa na magnitude e, especialmente, na melhor direção. Nesse último caso, ao contrário, pela diversidade e variedade de enfoques, pode estar representando uma fragmentação de visão e uma não-convergência de objetivos.

\footnotetext{
${ }^{2}$ Segundo o Diretório dos Grupos de Pesquisa 2002 do CNPq (http://lattes.cnpq.br/censo2002/sumula/index_sumula.htm, acessado em 28/10/2003), cerca de 85\% dos grupos de pesquisa concentram-se nas universidades públicas e segundo estatísticas da CAPES (http://www.capes.gov.br/, acessado em 28/10/2003), 82\% dos matriculados em cursos de mestrado e 96\% dos matriculados em doutorados o são em instituiçôes públicas.

${ }^{3}$ PROSAB - Programa de Pesquisa em Saneamento Básico, financiado por um conjunto de agências de fomento, lideradas pela FINEP (http://www.finep.gov.br/prosab/index.html)
} 


\section{PESQUISA EM SANEAMENTO: POR OUE, PARA QUE E PARA QUEM?}

A relevância da área de saneamento para o desenvolvimento do país encontra um reconhecimento quase consensual pelos diversos segmentos sociais, o que não tem guardado correspondência com a (baixa) prioridade tradicionalmente reservada ao setor. As inaceitáveis carências de atendimento populacional, as iniqüidades acumuladas, a insuficiente articulação intra e extra-setorial têm sido objeto de reiteradas constataçóes e de repetidas reivindicações visando à sua superação. Interessante observar que, mesmo autoridades governamentais de ciência e tecnologia vêm chamando a atenção para a essencialidade do setor ${ }^{4}$.

Contudo, limitar-se à constatação da importância da área de saneamento para o país e a sociedade, sem qualificar seu papel e sobretudo o benefício potencialmente dela esperado, pode ser insuficiente. Em especial quando não lastreada em evidências cientificamente sólidas, caso freqüente no setor.

Assim, tem sido usual se recorrer a tais constataçôes para validar financiamentos, programas e mesmo o fomento à pesquisa na área. Trata-se, em geral, de um diálogo de dentro para fora, dos agentes do setor com aqueles externos a ele, mas que detêm os recursos para impulsioná-lo.

Nessa perspectiva, questōes raramente debatidas são: a implantação de obras e instalações de saneamento, intrinsecamente, conduz a benefícios à população? A seleção tecnológica é independente da identificação e qualificação dos benefícios? Diante da reconhecida necessidade de ampliação da cobertura por saneamento, seria supérfluo discutir e comparar alternativas tecnológicas, diferentes modelos de gestão ou avaliar o impacto das soluçôes espontaneamente adotadas pela população? Seria também supérfluo avaliar a efetividade de programas e intervenções, visando retroalimentar concepçôes futuras?

Neste texto defende-se que a resposta a essas questôes deveria ser negativa. E que seria obrigação e responsabilidade do setor discutir-se; quanto às suas práticas, aos resultados de suas ações, às conveniências entre as diversas opçōes que se apresentam para resolver um proble- ma técnico, à decisão por um dado modelo de gestão, à validação de uma experiência empírica. E que tal discussão tem pertinência também no campo da pesquisa e desenvolvimento, já que, dado o quadro de carências e necessidades do setor, este também tem opçôes a realizar e rumos a tomar, diante de um leque de possibilidades.

Em suma, por que a pesquisa em saneamento? (com que sentido realizála?), para que realizá-la? (visando ao que?), para quem realizá-la? (existiriam, em situações específicas, populações alvo específicas?). Assume-se aqui que o debate acerca dessas indagaçóes cumpriria papel essencial em uma perspectiva de organizar o arcabouço conceitual da pesquisa na área, vislumbrando seu sentido, seus fins e seus cenários prospectivos. $E$ se indagando permanentemente sobre a contribuição dela esperada. Tarefa de responsabilidade dos dirigentes do setor e das agências de fomento à pesquisa, mas também de todos os militantes do cotidiano das pesquisas que, nessa qualidade, tomam decisões, mesmo não explicitamente, decisões essas que influem na direção - esta também não necessariamente explícitaque a política científica segue.

Em uma primeira aproximação, podem se discutir os fins a serem buscados com as açóes de saneamento no país, desde a formulação das políticas mais gerais até as ações operacionais e administrativas mais específicas. Nesse particular, dentre as formulaçôes construídas sobre um possível paradigma a ser perseguido pelas açóes setoriais, a seguinte pode ser mencionada, podendo representar uma de suas sínteses na atual conjuntura política do setor (OPAS, 2004):

- Universalidade: atendimento universal da população alvo das intervençôes.

- Eqüidade: equivalência na qualidade sanitária dos serviços, independente das condiçôes sócio-econômicas do usuário e da realidade urbanistica de onde vive.

- Integralidade: atendimento pelos serviços de saneamento com uma visão integral, que entenda o saneamento como um conjunto de açôes, envolvendo, pelo menos, o abastecimento de água, o esgotamento sanitário, a limpeza pública, a drenagem pluvial e o controle de vetores.

-Titularidade municipal: reconhecimento e respeito à autonomia municipal, em coerência com o preceito constitucional.
- Gestão pública: a compreensão de que os serviços de saneamento são, por definição, públicos, prestados sob regime de monopólio, essenciais e vitais para o funcionamento das cidades, para a determinação das condiçôes de vida da população urbana e rural, para a preservação do meio ambiente e para o desenvolvimento da economia.

- Participação e controle social: como requisito indispensável para tornar visivel e legitimada a diversidade de interesses, bem como para a apropriação dos equipamentos de saneamento pela população.

- Intersetorialidade: integração com o desenvolvimento urbano, a saúde pública e com as áreas ambiental e de recursos hidricos, entendida como indispensável para se atingir o pleno êxito das açōes, por natureza complexas.

- Qualidade dos serviços: incluindo a regularidade, a continuidade, a eficiência, a segurança, a atualidade, a cortesia e a modicidade dos custos.

- Acesso: compatibilização da política tarifária com o poder aquisitivo do usuário, mediante a prática da modicidade dos preços.

Além dos nove atributos defendidos como resultantes das políticas e programas de saneamento, a mesma referência propõe que devam ser avaliados os seguintes efeitos da ausência ou inadequação dos serviços: (i) efeitos sobre a saúde - morbi-mortalidade ampliada devido à inadequação de saneamento ambiental, (ii) efeitos de natureza ambiental - ecossistemas comprometidos; (iii) efeitos de natureza sócio-política exclusão social e redução dos níveis de cidadania. Trata-se de abordagem fundamental, pois é por meio da identificação dos efeitos possíveis e desejáveis das açôes de saneamento que efetivamente se poderão balizar escolhas e realizar avaliações, com implicaçôes claras nas opçōes de pesquisa na área.

Logo, a partir de um referencial tal como o apresentado, uma vez assumido como um padrão para os serviços, é possível se desencadear um debate sobre a distância entre a atual realidade do setor e tal padrão, identificando lacunas e necessidades e, como decorrência, estabelecendo diretrizes de pesquisa e desenvolvimento.

Outro importante aspecto é que a resposta às indagações objeto desta seção deve, necessariamente, considerar a reali-

${ }^{4} \mathrm{O}$ MCT, em sua publicação Programa de ciência e tecnologia para o desenvolvimento social (2002) afirma que "para os países em desenvolvimento, as inovaçóes nos campos do saneamento, despoluição de bacias hidrográficas, tratamento de resíduos sólidos, métodos de produção mais limpa, entre outros, significarão avanço considerável na preservação do meio ambiente, combate às doenças de veiculação hídrica e elevação da qualidade de vida das populações que habitam as periferias dos grandes centros urbanos". 
dade sócio-econômico-cultural do país, realidade sobre a qual os potenciais benefícios das ações e da pesquisa se aplicarão. Nesse particular, temas como o grau de desenvolvimento econômico do país, seus desequilíbrios sociais e ambientais e a maturidade das práticas políticas, vis-àvis com cenários prospectivos que se desenham nos planos político, econômico e social, são relevantes para situar a área de saneamento e pautar a pesquisa setorial.

Em paralelo, e por sua especificidade mais impactante, a realidade sanitária, decorrente das ações do próprio setor, deve se constituir em uma obrigatória moldura de referência para esse exercício. Aí, em primeiro lugar, uma visão analítica, a mais completa possível, do quadro de atendimento e de carências pelos serviços deve procurar ser traçado, à luz das informaçôes atualmente disponíveis, verificando a distribuição temporal e espacial dos diferentes serviços, bem como sua associação com variáveis demográficas, ambientais, sócio-econômicas e de saúde pública. Avaliações com essa abordagem podem ser encontradas em Heller et al, (2002).

Outra categoria de análise, possibilitada pelas bases mencionadas, destacando-se a PNSB - Pesquisa Nacional de Saneamento Básico, corresponde à distribuição da utilização de diferentes soluçôes técnicas, o que pode fornecer indícios sobre o padrão tecnológico dominante. Assim, o estágio atual do desenvolvimento tecnológico do setor pode ser avaliado, cotejando o conhecimento dominado pelas universidades, institutos de pesquisa e profissionais, com seu estágio atual de aplicação. A Tabela 1 ilustra uma das possibilidades de análise, revelando a proporção de sistemas no país que empregam a denominada técnica convencional de tratamento de água, inferior ao número de sistemas que captam água em mananciais superficiais (43\%), sugerindo imperfeiçôes no condicionamento da água para consumo humano.

Dimensão que necessita ser recuperada nessa discussão tecnológica refere-se ao grau em que as técnicas pesquisadas, desenvolvidas e aperfeiçoadas promovem, quando aplicadas em condições reais de campo, o benefício potencialmente idealizado, tanto em termos de seu funcionamento mais direto (e.g.: capacidade de um determinado processo de tratamento remover determinada substância), quanto em termos de seu benefício à população ou ao ambiente (e.g.: redução da ocorrência de dengue em população decor-

Tabela I - Percentual de distritos segundo a característica do sistema de água

\begin{tabular}{ccccccccc}
\hline Região/país & \multicolumn{3}{c}{$\begin{array}{c}\text { Número total } \\
\text { de distritos }\end{array}$} & \multicolumn{2}{c}{$\begin{array}{c}\text { Sem rede geral } \\
\text { de aua }\end{array}$} & \multicolumn{2}{c}{ Com tratamento } & \multicolumn{2}{c}{ Com tratamento } \\
& & $\mathrm{n}$ & $\%$ & $\mathrm{n}$ & $\%$ & $\mathrm{n}$ & $\%$ \\
\hline Norte & 607 & 95 & 15,65 & 219 & 36,08 & 86 & 14,17 \\
Nordeste & 3084 & 534 & 17,32 & 1925 & 62,42 & 847 & 27,46 \\
Sudeste & 3115 & 107 & 3,43 & 2163 & 69,44 & 1586 & 50,91 \\
$\quad$ Sul & 2342 & 375 & 16,01 & 1210 & 51,67 & 645 & 27,54 \\
Centro-Oeste & 700 & 81 & 11,57 & 529 & 75,57 & 249 & 35,57 \\
Brasil & 9848 & 1192 & 12,10 & 6046 & 61,39 & 3413 & 34,66 \\
\hline
\end{tabular}

Fonte: PNSB - 2000 (http://www.ibge.gov.br/)

rente da implantação de sistema de drenagem urbana). Obviamente, entre a solução técnica testada em condições experimentais controladas e a sua aplicação prática, atuam mediadores de diversas naturezas - operacionais, gerenciais, administrativos, econômicos, culturais - que determinam a maior ou menor efetividadeentendida como extensão em que uma intervenção, procedimento, ou serviço, quando empregados em campo em circunstâncias rotineiras, realiza o que se pretende que realize em uma população específica e diferencia-se de eficácia, entendida como extensão em que uma intervenção, procedimento, ou serviço, em condiçôes ideais, produz um resultado benéfico - do dispositivo ou do processo.

Dentre esses mediadores, relevante e crucial influência é exercida pela gestão dos serviços, podendo tanto potencializar quanto restringir os benefícios. Igualmente, tema fundamental nessa discussão é o da apropriação dos serviços pela população, na medida em que, dependendo das características sócio-culturais da comunidade objeto das intervenções, freqüentemente não é curta a distância entre as soluçôes concebidas pelos técnicos e a aderência a elas pelos pretensos beneficiários. Nesse particular, o impacto sobre a saúde de uma dada solução tecnológica em muitos casos dependerá, dentre outros aspectos:

- do diálogo com a população, durante a concepção das soluções;

- da proximidade entre gestores e população;

- de um processo continuado de avaliação do serviço;

- da integração entre a área de saneamento e outras áreas afins, sobretudo a de saúde;
- da retro-alimentação pela vigilância epidemiológica;

- da facilitação de mecanismos para a participação popular e o controle social;

- da prática de uma política tarifária inclusiva.

Para assegurar um enfoque científico - e menos "passional" - à discussão, cabe um esforço de avaliação das experiências já vivenciadas, bem como de perspectivas inovadoras de gestão dos serviços. Nesse ponto, é fundamental considerar o conceito de sustentabilidade dos sistemas, como atributo a ser buscado.

Ainda no contexto da gestão, necessidade incompletamente satisfeita no setor de saneamento refere-se ao tema do planejamento, especialmente incorporando dimensóes relacionadas à saúde pública. Embora o setor realize cotidianas opçōes sobre como e onde investir, em uma verdadeira definição de prioridades em tempos de recursos escassos, tais decisões raramente são lastreadas em critérios que considerem de forma objetiva os interesses da população beneficiada. Felizmente, algumas exceções recentes têm sido observadas a essa prática, como o critério de seleção de municípios a serem contemplados pelo Projeto Alvorada - o de apresentarem IDH inferior a 0,50 - e a Portaria 106/2004 (FUNASA, 2004), que estabelece critérios epidemiológicos para aplicação de recursos financeiros. A despeito disto, verifica-se uma carência de instrumentos metodologicamente bem elaborados, que suportem tais decisóes, observando-se algumas iniciativas iniciais nesse sentido (Teixeira \& Heller, 2001, 2003). 


\section{PESQUISA EM SANEAMENTO: O QUE PESOUISAR? (OS OBJETOS)}

Evidentemente, discussões sobre os por quês e para que $(\mathrm{m})$ pesquisar em saneamento, tais como desenvolvidas na seção anterior, constituem determinantes de base para a definição dos objetos da pesquisa. Nas diversas situações em que se efetuam escolhas sobre temas ou objetos de investigação - a definição de uma linha de pesquisa, o temário de um programa de pesquisa induzida, os objetivos de uma dissertação ou tese, o projeto submetido em atendimento a um edital - é fundamental a articulação de tal escolha com a visão de fundo desenvolvida anteriormente. O referido suporte conceitual propicia vislumbrar a direção com a qual a pesquisa se alinha, garante coerência interna para um conjunto de investigaçôes e, em síntese, proporciona organicidade e impede fragmentação de objetivos.

Independente da visão dos fins mais gerais a serem atingidos, a escolha dos objetos também se relaciona com a concepção particular sobre a sua posição na escala dos avanços científicos e tecnológicos exibidos pela área, conforme ilustrado pela Figura 1, onde se modelam perspectivas científicas a partir de duas visões extremas sobre o grau de evolução do campo de conhecimento.

Pela figura, observa-se que uma ou outra visão - e os inúmeros níveis intermediários na escala - podem demandar diferentes escolhas de objetos de investigação, determinando o balanceamento entre o grau de abstração e a investigação de campo.

Nesse particular, um esforço relevante seria o de localizar na literatura os objetos de investigação situados tanto na fronteira do conhecimento científico quanto os que procuram vislumbrar quebras de paradigmas dos padrões tecnológicos vigentes.

Assim, podem ser identificados, em relação ao abastecimento de água por exemplo, novos olhares sobre riscos quanto à presença de microrganismos na água produzida, eventualmente modificando padrôes tecnológicos e operacionais, a exemplo de protozoários e vírus, cianotoxinas e proliferação de organismos em biofilmes na distribuição de água. Discussão que já acumula algumas décadas, mas ainda incompleta, sobretudo nos países em desenvolvimento, relaciona-se

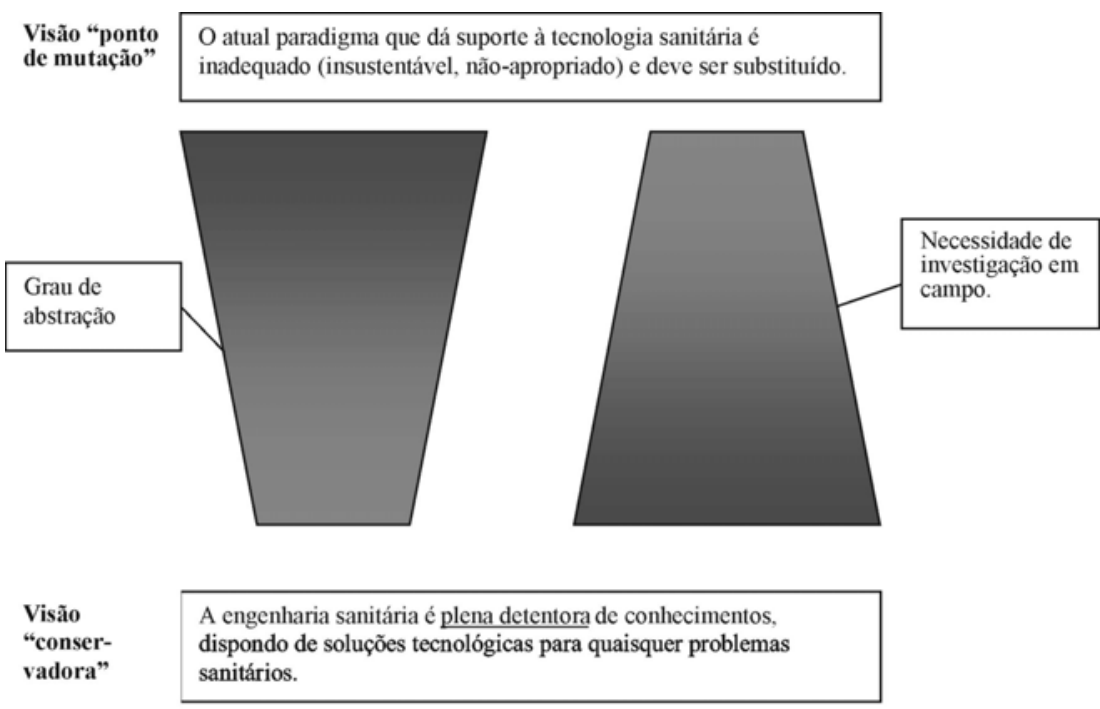
Figura I - Perspectivas científicas que podem condicionar a escolha de
objetos de investigação na área de saneamento

aos riscos de afecções crônicas - em especial neoplasias - decorrentes da utilização dos desinfetantes, em especial o cloro, nas águas de consumo, devido à formação de subprodutos. Ao lado de outros microcontaminantes, como aqueles que provocam perturbações endócrinas, a discussão sobre esses efeitos ganha destaque, em compasso com o aumento da longevidade da população.

Quanto ao esgotamento sanitário e ao manejo dos resíduos sólidos urbanos, estudiosos vêm chamando a atenção para a necessidade de se discutirem os paradigmas dominantes. Assim, o confronto entre soluçōes locais e soluçōes centralizadas e a valorização de técnicas que intensificam a reutilização dos efluentes líquidos e sólidos orientam novas perspectivas.

Semelhantes indagaçōes podem ser levantadas para o campo da drenagem, radicalizando concepçôes na vertente das denominadas soluções alternativas, propiciando maior harmonização ambiental e urbanística das intervenções para controle de enchentes e inundações.

Interessante constatação é a de que novas direções tecnológicas vêm tornando inseparáveis as diversas subáreas do saneamento, quanto à concepção sobre sua solução tecnológica, trazendo a indagação de se o futuro das diversas subáreas do saneamento resgatará a tão reclamada integralidade da área. Note-se que tal conceito acompanha as contemporâneas discussōes sobre as soluçôes duais (Okun, 2003), as estratégias para economia de água, o reuso intensivo de água, o ecological sanitation (Esrey 2001), soluções com separação da urina dos esgotos sanitários (Matsul et al., 2001); o water harvesting (Yuen et al., 2001), integração da disposição de resíduos com a produção de alimentos (Mara, 2001), técnicas de descentralização radical de soluções para o abastecimento de água e a disposição de efluentes e resíduos. O campo dos recursos hídricos, por sinal, tem importantes contribuiçôes a oferecer, na consolidação das bases para a adoção da bacia hidrográfica como unidade central e estruturadora do planejamento e da gestão do saneamento.

Algumas experiências na perspectiva de identificação de temas de pesquisa em saneamento têm sido observadas no país. Identifica-se inicialmente o estudo Prospectar do MCT (MCT, 2003). Além disto, deve ser mencionado o PROSAB, que vem adotando a definição de temas por meio de discussão em um grupo coordenador, composto por representantes de vários segmentos do setor, muitas vezes consultando técnicos e pesquisadores da área, em pesquisa aberta de opiniāo. Outra iniciativa origina-se do próprio MCT, em documento específico com identificação de pesquisas, visando à contribuição para o desenvolvimento social (MCT, 2001).

No plano internacional, também se identificam iniciativas de prospecção de temas de pesquisas no campo do saneamento, a exemplo do trabalho desenvolvido pelo Comitê de Investigação em Engenharia Ambiental da Divisão de Engenharia Ambiental da ASCE na dé- 
cada de 1970 (Jeed, 1973), quando, após processo participativo envolvendo pesquisadores e técnicos norte-americanos, foram listados 42 tópicos nas áreas de esgotamento sanitário, resíduos sólidos, recursos hídricos, tratamento de água, "saneamento ambiental" (soluçôes individuais para a disposição de esgotos, soluções individuais para o abastecimento de água, poluição atmosférica intra-domiciliar, controle de vetores) e poluição atmosférica.

\section{PESQUISA EM SANEAMENTO: COMO PESQUISAR? (OS CAMPOS CIENTIFICOS, A NATUREZA DA INVESTIGAÇÃO, OS MÉTODOS)}

A discussão sobre os vários contornos da forma como se processa e deve se processar a investigação científica pode também ser iniciada localizando-se as visôes prevalentes quanto à contribuição científica demandada, relacionada com a avaliação do grau de desenvolvimento científico e tecnológico alcançado pela área. A Figura 2 pode contribuir para vislumbrar as possibilidades de enfoque, a partir de duas plausíveis visões extremas.

Pela figura, observa-se que uma ou outra visão - e os inúmeros níveis intermediários na escala - podem implicar diferentes escolhas de estratégias metodológicas de investigação, determinando o balanceamento entre pesquisa básica ou aplicada - e adaptaçôes e aperfeiçoamentos tecnológicos.

Essa abordagem sinaliza para a necessidade de um trabalho de classificação das categorias de pesquisa em saneamento adotadas, uma vez que cada estratégia metodológica conduz a diferentes possibilidades de produção de conhecimento. Como exemplo, o quadro a seguir, elaborado por ocasião da avaliação do PROSAB, ilustra uma possível classificação de um conjunto de pesquisas fomentadas.

Por outro lado, esta como outras áreas de conhecimento no país exibe grupos de pesquisa com diferentes graus de amadurecimento científico. E, nesse ponto, observa-se outra carência: a da formação sólida dos pesquisadores sobre método científico, com capacidade de visão crítica de sua aplicação e mesmo da visualização das (pós) modernas tendências epistemológicas (Santos, 2002). Tal esforço deverá incluir a elaboração de documentos qualificados, setorialmente

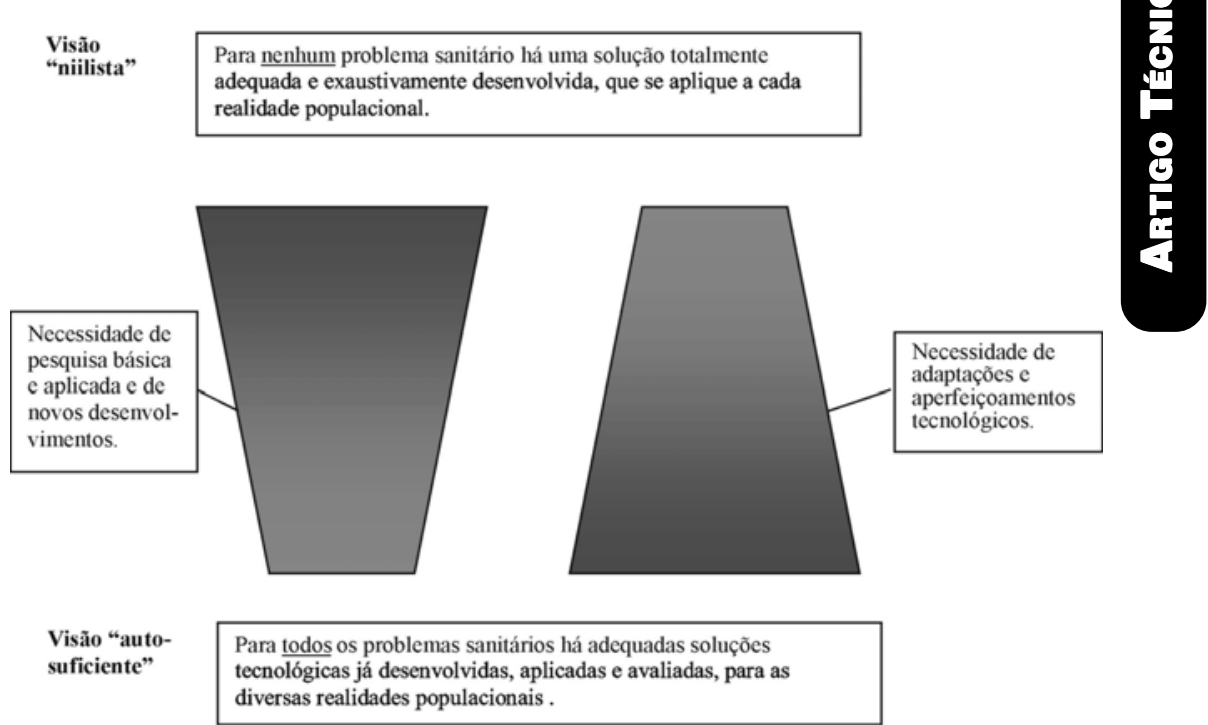

Figura 2 - Perspectivas científicas que podem condicionar a metodologia de investigação na área de saneamento

mais específicos, a exemplo da iniciativa, ainda que modesta, da série de artigos: Heller et al. (1996), von Sperling et al. (1996) e Nascimento et al. (1996).

Em linha de formulação epistemológica, Crotty (1998, apud Creswell, 2003) sugere que, ao se elaborar uma proposta de investigação, quatro questões devem ser consideradas:

- Qual epistemologia - teoria do conhecimento ancorada na perspectiva teórica - dá suporte à pesquisa?

- Qual perspectiva teórica - posição filosófica - é subjacente à a metodologia em questão?

-Qual metodologia - estratégia ou plano de ação que conecta métodos com resultados - governa a escolha e o uso de métodos?

- Quais métodos - técnicas e procedimentos - se propõem a usar (questionário, entrevista, grupo focal)?

Mesmo que esta abordagem tenha maior aplicação à área das ciências humanas, ela evidencia a necessidade de precisão das escolhas adotadas no planejamento das pesquisas, escolhas estas que podem condicionar as contribuições delas esperadas. Uma mais completa nitidez nesses aspectos pode potencializar a elaboração de projetos, o desenvolvimento de pesquisas e sua própria avaliação.

Por fim, deve ser relembrada a freqüente complexidade do objeto saneamento, em suas diversas facetas temáticas, o que re-enfatiza a necessidade de emprego de métodos adequados e o reconhecimento de seus múltiplos tentáculos. Assim, a pesquisa interdisciplinar e a apro- ximação com outras áreas de conhecimento - oriundas das ciências físicas, químicas, biológicas, da saúde e humanas mostram-se imperativos para um adequado resultado da tarefa de desvendar as verdades desses objetos.

\section{TÓPICOS ADICIONAIS ENVOLVIDOS}

Além dos pontos abordados no presente artigo, saliente-se que há uma gama de questôes adicionais a serem desenvolvidas, ao se procurar uma formulação mais completa sobre a pesquisa na área. Citam-se as seguintes:

- Formação de recursos humanos

Uma política efetiva de pesquisa na área de saneamento deve cuidar de avaliar as necessidades de formação de pesquisadores em seus diversos níveis de formação - com ênfase para a formação de doutores - vis-à-vis a capacidade e potencialidade nacionais de formação de recursos humanos, complementada pela identificação de instituições internacionais com perfil adequado para tanto. Nesse contexto, deve-se também entender a formação como instrumento para a transferência de tecnologia.

- Divulgação científica e
tecnológica
Aspecto fundamental nessa discus-
são consiste na identificação das formas e
veículos disponíveis para a disseminação
do conhecimento produzido nas pesqui-
sas e para a transferência de tecnologia,


Tabela 2 - PROSAB- IV Seminário de Avaliação. Classificação das categorias de pesquisas desenvolvidas

\begin{tabular}{|c|c|c|}
\hline $\begin{array}{l}\text { Categorias dos sub-projetos, } \\
\text { segundo a natureza das pesquisas }\end{array}$ & Observação & Exemplos \\
\hline Projetos de intervenção & $\begin{array}{c}\text { Baixa capacidade de } \\
\text { generalização de resultados e } \\
\text { otimização de parâmetros }\end{array}$ & $\begin{array}{l}\text { Implantação de unidades municipais } \\
\text { (lixo); implantação de instalação em } \\
\text { campus universitário (água) }\end{array}$ \\
\hline Avaliação de tecnologias & $\begin{array}{l}\text { Privilegia a comprovação e } \\
\text { avaliação de eficiência, sob } \\
\text { condições locais/nacionais }\end{array}$ & $\begin{array}{l}\text { Avaliação de unidades em escala } \\
\text { piloto, sem comparação entre } \\
\text { diferentes condições; avaliação de } \\
\text { instalações em escala real }\end{array}$ \\
\hline $\begin{array}{l}\text { Otimização de parâmetros de } \\
\text { projeto e de métodos } \\
\text { operacionais }\end{array}$ & $\begin{array}{c}\text { Contribui para a inferência sobre } \\
\text { condiçōes ótimas de projeto e de } \\
\text { operação para condições } \\
\text { locais/nacionais }\end{array}$ & $\begin{array}{l}\text { Projetos que testam diferentes } \\
\text { unidades piloto, comparando } \\
\text { diferentes condições de } \\
\text { funcionamento }\end{array}$ \\
\hline Desenvolvimento de modelos & $\begin{array}{l}\text { Permite simulações e predições } \\
\text { para condiçóes locais/nacionais }\end{array}$ & $\begin{array}{l}\text { Modelagem de percolação em } \\
\text { processos de disposição de resíduos }\end{array}$ \\
\hline $\begin{array}{l}\text { Padronização de métodos } \\
\text { analíticos }\end{array}$ & $\begin{array}{l}\text { Garante comparabilidade dos } \\
\text { resultados, inclusive de } \\
\text { investigaçôes futuras }\end{array}$ & $\begin{array}{l}\text { Métodos analíticos para } \\
\text { resíduos sólidos }\end{array}$ \\
\hline Desenvolvimento & $\begin{array}{l}\text { Importante produto das } \\
\text { pesquisas, no sentido da } \\
\text { inovação tecnológica }\end{array}$ & $\begin{array}{l}\text { Processo para calagem de lodo; } \\
\text { softwares (apoio à decisão, seleção de } \\
\text { áreas para disposição de resíduos) }\end{array}$ \\
\hline Redação de livros técnicos & $\begin{array}{l}\text { Sistematizando estado-da-arte da } \\
\text { área e gerando material para } \\
\text { divulgação e formação }\end{array}$ & \\
\hline
\end{tabular}

Fonte: Heller, L. Síntese da avaliação. PROSAB. IV Seminário de avaliação. Dezembro/2001.

avaliando-os criticamente e identificando necessidades de fomento e criação de novas modalidades de disseminação. Devese, nesse particular, reconhecer o potencial multiplicador da divulgação por meio dos periódicos científicos e o instituto da indexação científica como pré-requisito para garantir a amplitude e a abrangência da disseminação científica. Aí, cabe uma adequada identificação dos periódicos da área ou que com ela estabelecem interfaces, avaliando o parque de periódicos nacionais à disposição para a divulgação e eventuais esforços a serem despendidos pela política científica da área, visando ao seu aperfeiçoamento. De uma outra perspectiva, há que se assegurar o mais amplo acesso da comunidade científica aos periódicos internacionais relevantes da área. Nesse particular, a despeito da louvável iniciativa de implantação do portal de periódicos da CAPES, cumpre destacar a atual ausência nele dos principais periódicos dos campos da Engenharia Sanitária e Ambiental e dos Recursos Hídricos.

- Transferência de tecnologia

Transferência de tecnologia tem sido um tema sobre o qual segmentos de pes- quisadores da área vêm refletindo. Particularmente, o PROSAB vem identificando a necessidade de promovê-la, buscando avançar "da academia para a incorporação aos serviços" o desenvolvimento alcançado. Nesse campo, parece indispensável uma formulação mais estratégica, aliada a uma articulação entre agências de fomento, pesquisadores e prestadores de serviços, para tornar efetivo o processo. mento

- Fomento da pesquisa em sanea-

Este talvez seja o principal corolário das reflexões desenvolvidas neste texto: a necessidade de uma formulação consistente, global, articulada e integralizadora para as pesquisas na área. A associação entre a essencialidade da área, os desafios científicos e tecnológicos identificados e a fragmentação do fomento científico e tecnológico fortalecem essa necessidade. Para tanto, a implementação de uma política científica setorial com tais atributos - antecedida por um planejamento mostra-se essencial para assegurar a organicidade da pesquisa em saneamento.
- Avaliação da pesquisa

Ao lado de um esforço de fomento, e como pré-requisito para seu êxito, localiza-se o esforço de avaliação. Nesse caso, merece atenção tanto a avaliação do atual estado científico da área e das pesquisas mais recentemente concluídas, quanto uma estratégia de avaliação continuada de futuras investigaçōes, grupos, linhas e projetos de pesquisa a serem financiados, sobretudo se o forem no bojo de uma política setorial específica.

\section{UM POSSÍVEL PROTOCOLO PARA CLASSIFICACCÁO E SELECÁO DÉ PESOUISA E DESENVOLVIMENTO EM SANEAMENTO}

Visando ilustrar a construção de um possível modelo para classificação das pesquisas em saneamento e avaliar sua aplicabilidade, desenvolveu-se um protocolo tentativo. Como exercício, aplicouse tal instrumento junto a pesquisadores do Departamento de Engenharia Sanitária e Ambiental da UFMG, obtendo-se uma relação de temas de pesquisas e de- 
senvolvimento, classificados conforme o instrumento proposto.

Em seu desenvolvimento, consideraram-se cinco dimensões para a classificação das pesquisas, a saber:

\section{Dimensão I: da natureza da investigação}

Em relação à natureza científicotecnológica pela qual a $\mathrm{P} \& \mathrm{D}$ pode ser classificada, dentre as diferentes possíveis definições, foram adotadas, em um primeiro momento, as seguintes:

- Pesquisa básica: definida como "trabalho experimental ou teórico realizado primordialmente para adquirir novos conhecimentos sobre os fundamentos de fatos ou fenômenos observáveis, sem o propósito de qualquer aplicação ou utilização" (OCED, 1993) (grifos do autor), ou seja, "o pesquisador da ciência básica trabalha com problemas que a ele interessam (por motivos cognoscitivos)" (Bunge, 1980).

- Pesquisa aplicada: “investigação original, realizada com a finalidade de obter novos conhecimentos, mas dirigida, primordialmente, a um objetivo prático" (OCDE, 1993) (grifos do autor), em que o pesquisador estuda os problemas de possível interesse para a sociedade (Bunge, 1980).

- Desenvolvimento tecnológico: "trabalho sistemático, apoiado no conhecimento existente, adquirido por pesquisas ou pela experiência prática, dirigido para a produção de novos materiais, produtos ou equipamentos, para a instalação de novos processos, sistemas ou serviços ou para melhorar substancialmente aqueles já produzidos ou instalados" (desenvolvimento experimental) (OCDE, 1993); emprega parte do conhecimento científico, somado ao conhecimento para projetar artefatos e planejar linhas de ação, que tenham algum valor prático para algum grupo social (técnica) (Bunge, 1980)..

Âs três definições anteriores, identifica-se, no campo do saneamento, a necessidade de se agregar uma abordagem adicional, complementar àquelas classicamente definidas como natureza da pesquisa, em vista do uso encontrado nos resultados tecnológicos da pesquisa em saneamento, de cujo êxito dependem as condições objetivas da realidade em que são aplicados:

- Avaliação de efetividade, na acepção já definida neste texto e cuja importância se manifesta na medida em que pode contribuir para avaliar a aplicabi- lidade das técnicas em uso, inclusive daquelas fruto de desenvolvimento tecnológico mais recente, em uma situação real, qual seja, mediada por fatores políticos, administrativos, urbanísticos, sócio-culturais, com suas variaçōes ditadas pela gama de realidades encontradas no país.

Considerando os objetivos do protocolo a ser aplicado, dentre os itens apresentados, selecionaram-se as seguintes quatro categorias para comporem a dimensão:

- Pesquisa básica ou aplicada, admitindo-se que reduzidos ganhos seriam obtidos com a diferenciação, já que a quase totalidade das abordagens na área classifica-se como pesquisa aplicada.

-Novos desenvolvimentos tecnológicos, voltados para a concepção e testes de novos produtos, equipamentos, materiais ou processos, incluindo nestes últimos modelos de gestão.

- Adaptações e aperfeiçoamentos tecnológicos, voltados para a otimização e aperfeiçoamento dos produtos, equipamentos, materiais ou processos já produzidos ou instalados.

- Avaliação de efetividade, de produtos, equipamentos, materiais ou processos.

\section{Dimensão 2: do objeto da pesquisa}

Em função do grau de emergência ou de consolidação de uma determinada técnica ou de um determinado problema sanitário, diferentes estratégias, prioridades ou enfoques científicos podem ser estabelecidos. Em vista disso, selecionaram-se quatro categorias para esta segunda dimensão:

- Novos paradigmas científicos e tecnológicos: categoria que vislumbra debates em curso ou em emergência, que visam redirecionar o atual padrão tecnológico dominante.

- Técnicas emergentes e "novos" problemas sanitários: incluindo aqueles problemas sanitários sobre os quais ainda não se dominam inteiramente sua importância e as técnicas a serem empregadas para sua solução, além daquelas técnicas insuficientemente dominadas.

- Técnicas consolidadas, porém que ainda demandam aperfeiçoamentos, otimizaçôes, compreensão de aspectos particulares do seu comportamento, avaliações de seu desempenho, avaliações de impactos ou proteção sobre a saúde e o ambiente.

- Investigações sobre modelos e estratégias de gestão, incluindo: (i) a gestão técnica e político-administrativa de serviços, de sistemas e de suas partes (e.g.: coleta de resíduos sólidos urbanos); (ii) modelos de gestão, abrangendo o papel do poder público, a participação da população e métodos de controle social; (iii) avaliação de políticas, por exemplo as que incentivam a participação da iniciativa privada.

\section{Dimensão 3: da relevância}

A relevância de um elenco de temas de pesquisa pode ser estabelecida com base em uma gama de critérios, que podem envolver os conceitos de relevância científica, relevância social, relevância política (habilidade em resultar em potencialização da participação popular...), relevância econômica (potencial em resultar em benefícios econômicos), dentre outros. A definição do grau de relevância de determinado tema é, em geral, fruto da perspectiva dominante de quem estabelece a classificação. Assim sendo, é provável que a prospecção de relevância tenha seu melhor resultado a partir de consulta a grupos de opiniāo, criteriosamente compostos.

Em vista disto, optou-se, no presente exercício, por não se estabelecerem graus de relevância e não solicitar dos respondentes tal definição, a menos da recomendação de que, caso identificados temas de alta relevância pelo entrevistado, tal aspecto fosse registrado.

\section{Dimensão 4: da população alvo}

Importante dimensão em uma classificação dessa natureza seria a identificação da população alvo da técnica em análise ou em desenvolvimento. Em um país com a realidade como a nossa, importa, em muitas aplicações, diferenciar a característica sócio-cultural da população ou a característica urbanística do assentamento populacional, uma vez que as soluções podem (e alguns casos devem) diferir de situação para situação. Saliente-se ainda que o quadro de atendimento pelos serviços atualmente apresentado pelo país exibe uma nítida associação entre as carências de atendimento e a população excluída socialmente, ou seja, muitas das soluções de saneamento que o país demanda localizam-se justamente em área com ocupação urbana não-convencional, que reúne populações com características culturais particulares.

Nesse contexto, caberiam diferenciaçōes, como: população urbana/popu- 
lação rural; população urbana moradora em locais de urbanização convencional/ população urbana moradora em locais de urbanização precária (vilas, favelas, invasões); populações especiais (indígenas...).

Caberia ainda pensar em uma separação entre técnicas/problemas de abrangência universal e técnicas/problemas predominantemente característicos de países em desenvolvimento.

De forma semelhante à dimensão anterior, optou-se, neste momento, por não assumir esta como uma dimensão para efeito de classificação, mas também recomendar aos respondentes que destacassem tal particularidade, quando aplicável.

\section{Dimensão 5: da subárea}

Considerando as muito relevantes particularidades características de cada subárea componente do saneamento, optou-se por destacá-las e consultar os especialistas de cada uma delas independentemente. Adotou-se a seguinte classificação:

- Abastecimento de água;

- Esgotamento sanitário (incluindo o lodo resultante do tratamento);

- Gerenciamento de resíduos sólidos urbanos;

- Drenagem urbana.

Em vista das formulações anteriormente apresentadas, construiu-se o protocolo, que, separadamente por subárea (dimensão 5), privilegia a combinação entre as dimensões 1 e 2.

A Tabela 3 resume a freqüência de respostas, em um total de 49 temas, por campo do protocolo. $\mathrm{Na}$ Tabela 4 encontram-se os resultados obtidos com sua aplicação aos subtemas abastecimento de água, esgotamento sanitário e resíduos sólidos urbanos, gentilmente respondidos, como um exercício de aplicação, por professores pesquisadores da UFMG. Saliente-se que não foi aplicado o protocolo para o tema de drenagem urbana, uma vez que o subtema foi objeto de reflexão específica, no âmbito do exercício de prospecção (Nascimento \& Heller, 2004).

Sem se analisar o conteúdo das respostas em si, que evidentemente devem ser objeto de debate entre especialistas nas respectivas subáreas, observa-se quantitativamente uma maior incidência de temas (em número de seis) em:

- Técnicas emergentes e "novos" problemas sanitários/Pesquisa.

- Técnicas emergentes e "novos" problemas sanitários/Adaptaçôes e aperfeiçoamentos tecnológicos.

Tabela 3- Freqüência de respostas ao protocolo para classificação e seleção de pesquisas por campo de classificação

\begin{tabular}{ccccc}
\hline Natureza & \multicolumn{3}{c}{ Objeto } & \\
& $\begin{array}{c}\text { Novos paradigmas } \\
\text { científicos e } \\
\text { tecnológicos }\end{array}$ & $\begin{array}{c}\text { Técnicas emergentes e } \\
\text { "novos" problemas } \\
\text { sanitários }\end{array}$ & $\begin{array}{c}\text { Técnicas } \\
\text { consolidadas }\end{array}$ & $\begin{array}{c}\text { Modelos e } \\
\text { estratégias } \\
\text { de gestão }\end{array}$ \\
\hline Pesquisa & AA (1) & AA (3) & AA (1) & AA (1) \\
(básica/aplicada) & ES (1) (4) & ES (1) (6) & ES (1) (3) & ES (1) (4) \\
Novos & RA (2) & RS (2) & RS (1) & RS (2) \\
desenvolvimentos & RS (2) (3) & AA (1) & ES (3) (4) & RS (2) (3) \\
tecnológicos & AA (1) & AA (1) & ES (2) & RS (1) (1) \\
Adaptaçóes e & ES (1) (2) & ES (3) (6) & RS (1) (3) & \\
aperfeiçoamentos \\
tecnológicos
\end{tabular}

Legenda: AA: abastecimento de água; ES: esgotamento sanitário; RS: resíduos sólidos urbanos

Por outro lado, nenhum tema foi classificado no campo Técnicas consolidadas/ Novos desenvolvimentos tecnológicos.

Sob o ponto de vista da adequação do instrumento, a aplicação não permitiu avaliá-la em detalhes, o que seria possível apenas após uma aplicação mais abrangente e sua discussão em uma oficina de trabalho, mas se observou que em um primeiro momento o protocolo suscitou dúvidas que, uma vez esclarecidas, propiciou o preenchimento por parte dos pesquisadores.

\section{CONCLUSÕES E RECOMENDAÇỐES}

O presente artigo buscou abordar as várias dimensões envolvidas na pesquisa e desenvolvimento em saneamento, à luz da realidade nacional. Ao se avaliar cada uma dessas dimensões, pode se especular que existe um conjunto de carências no tema, as quais podem ser sintetizadas por meio das seguintes necessidades:

- Resgate, em detalhes, da história da pesquisa em saneamento no Brasil, identificando os eventos mais relevantes.

- Inventário das diversas iniciativas e programas atualmente existentes que, direta ou indiretamente, apóiam a pesquisa na área.

- Avaliação da base social sobre a qual se sustenta a pesquisa em saneamento, vislumbrando sua pertinência e sua relevância.

- Debate sobre os objetos da investigação, vislumbrando a sua base conceitual de suporte.

- Debate metodológico sobre a pesquisa e desenvolvimento em saneamento.
- Formulações consistentes sobre a formação de recursos humanos para a pesquisa, a divulgação científica e tecnológica, a transferência de tecnologia, o fomento e a avaliação da pesquisa.

- Prospecção sobre temas de investigação, a partir de protocolo e metodologia apropriados.

Pode-se finalmente constatar que, se a pesquisa em saneamento atualmenteéapoiada por um razoável número de iniciativas e programas, de caráter induzido ou não, o somatório de tais esforços não conduz a uma direção intencional. Ou seja, o conjunto de iniciativas e programas atuais não pode ser considerado uma política de investigação na área, política esta essencial, considerando a essencialidade da área e a reconhecida necessidade de a pesquisa científica e tecnológica contribuírem, em curto espaço de tempo, para a superação das perversas carências populacionais exibidas pelo setor no país.

Em vista disto, finaliza o presente texto a proposta de que se organize uma conjunção de esforços dos diversos segmentos relacionados à pesquisa em saneamento - agências de fomento, órgãos federais que coordenam o setor, prestadores de serviço, organizações técnicas e profissionais - no sentido de se desenvolver um planejamento das pesquisas na área. Fundamental seria que tal planejamento recebesse olhares e perspectivas de outras áreas de conhecimento e da própria sociedade civil, representando os provedores dos recursos públicos e beneficiários finais dos resultados das pesquisas, no sentido de oxigenar a visão endógena com outros pontos de vista enriquecedores. Propóe-se que esse processo de reflexões culmine com 


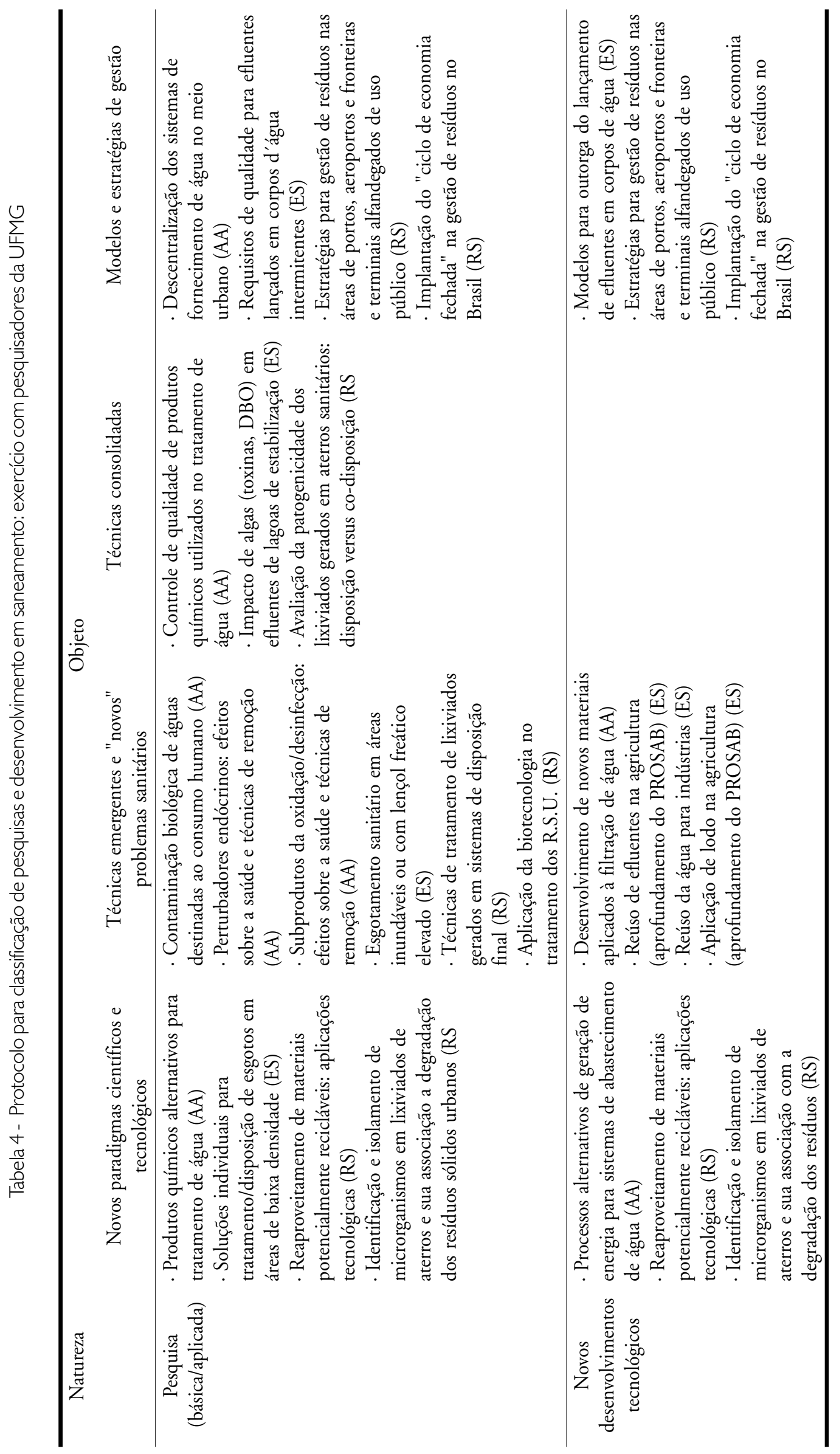




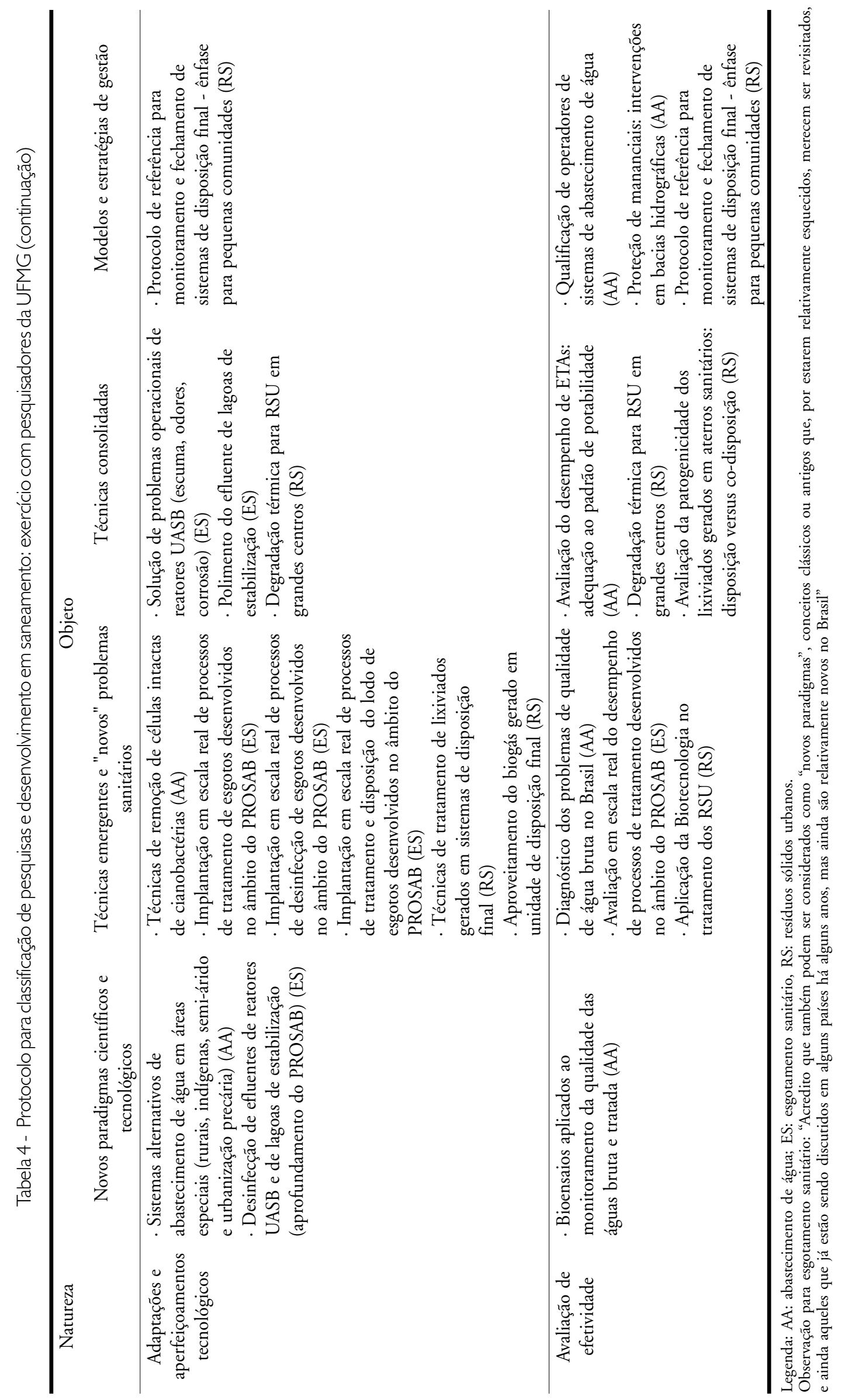


a elaboração de um plano diretor de pesquisas em saneamento, que forneça as bases e respalde uma futura política de pesquisas na área.

\section{AGRADECIMENTOS}

Os autores gostariam de manifestar seu agradecimento aos Professores Liséte Celina Lange, Marcos von Sperling e Valter Lúcio de Pádua, do Departamento de Engenharia Sanitária e Ambiental da UFMG, por sua disposição e solidariedade na discussão e preenchimento do protocolo de prospecção, e ao CGEE pelo financiamento do estudo.

\section{REFERÊNCIAS}

BUNGE, M. Ciência e desenvolvimento. Belo Horizonte: Ed. Itatiaia, 133p. 1980.

BUNGE, M. Teoria e realidade. São Paulo: Perspectiva, 170p. 1974.

CRESSWELL, J.W. Research design: qualitative, quantitative, and mixed methods approaches. 2 ed. Thousand Oaks: Sage, 2003.

CROTTY, M. The foundations of social research: meaning and perspective in the research process. Londres: Sage, 1998 apud CRESSWELL, J.W. Research design: qualitative, quantitative, and mixed methods approaches. 2 ed. Thousand Oaks: Sage, 2003.

ENNES, Y.M. A pesquisa universitária e suas interfaces: entre o faz-de-conta e o vamos ver! Revista BIO, v.3, n.4, p.19-25. 1991.

ESREY, S. A. Towards a recycling society: ecological sanitation - closing the loop to food security. Water Science \& Technology, v. 43, n. 4, p. 177-87. 2001.

FUNASA - Fundação Nacional da Saúde. Portaria 106/2004. Aprova os critérios e os procedimentos básicos para aplicação de recursos financeiros. Brasília. 04 mar. 2004.

HELLER, L. PROSAB III: Sintese da avaliação. Florianópolis: IV Seminário de avaliação do PROSAB, 6p. 2001.

HELLER, L.; NASCIMENTO, N. O.; PAIVA, J. E. M. Saneamento. In: BDMG. Minas Gerais do século XXI. Belo Horizonte: Rona Editora, v. 3: Infra-estrutura: sustentando o desenvolvimento, p. 245-300. 2002.

HELLER, L.; NASCIMENTO, N.O.; VON SPERLING, M. Investigação cientifica em engenharia sanitária e ambiental. Parte 1: o delineamento experimental. Revista Engenharia Sanitária e Ambiental, v. 1, n. 2, p. 33-43, abr.-jun. 1996.

IBGE - INSTITUTO BRASILEIRO DE GEOGRAFIA E ESTATÍSTICA. Censo demográfico 2000. Características da população e dos domicílios. Rio de Janeiro: Fundação IBGE, 2001.

IBGE - INSTITUTO BRASILEIRO DE GEOGRAFIA E ESTATÍSTICA. Pesquisa nacional de saneamento básico - 2000. Disponível em: <http://www.ibge.gov.br/>. Acesso em: jun. 2003.
LAST, J.M. A dictionary of epidemiology. 4ed. Oxford: International Epidemiological Association, 2001.

MARA, D. D. Appropriate wastewater collection, treatment and reuse in developing countries. Proceedings of the Institution of $\mathrm{Ci}$ vil Engineers - Municipal Engineer, v. 145, n. 4, p. 299-303, 2001.

MATSUI, S.; et al. Emerging paradigms in water supply and sanitation. In: MAKSIMOVIC, C. TJADA-GUIBERT, J.A. Frontiers in urban water management: deadlock or hope. Londres: IWA Publishing, UNESCO. 2001.

Ministério da Ciência e Tecnologia - MCT. Programa de ciência e tecnologia para o desenvolvimento social. Brasília: MCT, 76p. 2002.

Ministério da Ciência e Tecnologia - MCT. Programa Prospectar. Disponível em: <http:// www.mct.gov.br/cct/prospectar/>. Acesso em: 25 jun. 2003.

NASCIMENTO, N.O.; HELLER, L. Ciência, tecnologia e inovação na interface entre as áreas de recursos hidricos e saneamento. Revista Engenharia Sanitária e Ambiental, v. 10, n. 1, p. 36-48, jan.-mar. 2005.

NASCIMENTO, N.O., et al. Investigação cientifica em engenharia sanitária e ambiental. Parte 3: análise estatística de dados e de modelos. Revista Engenharia Sanitária e Ambiental, v. 1, n. 4, p. 152-168, out.-dez. 1996.

OCDE. Manual Frascati, 1993 apud SILVA, C.G.; MELO, L.C.P. (coord.). Ciência, tecnologia e inovação: desafio para a sociedade brasileira (Livro verde). Brasília: MCT/Academia Brasileira de Ciências. 2001.

OPAS - ORGANIZAÇÃO PAN-AMERICANA DA SAÚDE. Proposta metodológica de avaliação do impacto na saúde das açôes de saneamento: subprojetos de saneamento e antropologia. Brasília: OPAS, 108p. 2004.

OKUN, D. A. Water reuse introduces the need to integrate both water supply and wastewater management at local and regulatory levels. Water Science and Technology, v. 46, n. 6/7, p. 273-280. 2003.

Research needs in environmental engineering in water resources, water treatment, environmental sanitation and air pollution. Journal of the Environmental Engineering Division, v. 99, n. EE6, p. 801-812, 1973.

SANTOS, B.S. Um discurso sobre as ciências. 13 ed. Porto: Afrontamento. 2002.

SILVA, C.G.; MELO, L.C.P. (coord.). Ciência, tecnologia e inovação: desafio para a sociedade brasileira (Livro verde). Brasília: Ministério da Ciência e Tecnologia/Academia Brasileira de Ciências, 278p. 2001.

TEIXEIRA, J.C.; HELLER, L. Modelo de priorização de investimentos em saneamento com enfase em indicadores de saúde: desenvolvimento e aplicação em uma companhia estadual. Revista Engenharia Sanitária e Ambiental, v.6, n.34, p. 138-146, jul.-dez. 2001.

TEIXEIRA, J.C.; HELLER, L. Priorização de investimentos em saneamento baseada em indicadores epidemiológico e financeiro. Revista Engenharia Sanitária e Ambiental, v.8, n.3, p.187-194, jul.-set. 2003.
VON SPERLING, M.; HELLER, L.; NASCIMENTO, N.O. Investigação científica em engenharia sanitária e ambiental. Parte 2: a análise preliminar dos dados. Revista Engenharia Sanitária e Ambiental, v. 1, n. 3, p. 115-124, jul.-set. 1996.

YUEN, E., et al. Water harvesting techniques for small communities in arid areas. Water Science \& Technology, v. 44, n. 6, p. 189-94, 2001.

\section{Endereço para correspondência:}

\author{
Léo Heller \\ Universidade Federal de Minas \\ Gerais \\ Dep. de Engenharia Sanitária e \\ Ambiental \\ Av. do Contorno, 842 - $7^{\circ}$ Andar \\ 30 I30-000 Belo Horizonte - MG - \\ Brasil \\ Tel: (3I) 3238-1978 \\ E-mail: heller@desa.ufmg.br
}

